\title{
Neuropsychological and neuroradiological correlates in Huntington's disease
}

\author{
SERGIO E STARKSTEIN, JASON BRANDT, SUSAN FOLSTEIN, \\ MILTON STRAUSS, MARCELO L BERTHIER, GODFREY D PEARLSON, \\ DEAN WONG, ANNE MCDONNELL, MARSHAL FOLSTEIN
}

From the Department of Psychiatry and Behavioral Sciences, Johns Hopkins University School of Medicine, Baltimore, MD, USA

SUMMARY Measurements of cortical and subcortical atrophy were made on CT scans of 34 patients with Huntington's disease. Significant correlations were found between the bicaudate ratio (BCR) and an eye movement scale $(r=0.44, p<0.01)$, and activities of daily living scale $(r=0.57$, $\mathrm{p}<0.001)$ and the Mini-Mental State Exam $(r=0.49, \mathrm{p}<0.01)$. No correlations were found between BCR values and severity of chorea or voluntary motor impairment. A detailed neuropsychological evaluation of 18 Huntington's disease patients showed significant correlations between the BCR and Symbol Digit Modalities test $(r=0.65, p<0.01)$, and parts $A(r=0.72$, $\mathrm{p}<0.001)$ and $\mathrm{B}(\mathrm{r}=0.80, \mathrm{p}<0.0001)$ of the Trail Making Test. These data support work in primates that demonstrates the role of the caudate nucleus in cognitive and oculomotor functions, but not in motor control (which is governed by putamino-subthalamic systems). The specific cognitive skills correlated with caudate atrophy in Huntington's disease are those reported in primate work to be served by the frontal-caudate loop system: eye movements, conceptual tracking, set shifting and psychomotor speed.

Huntington's disease is a progressive neurodegenerative disorder inherited as an autosomal dominant trait. Symptoms which usually begin in the fourth or fifth decade of life, include abnormal movements, cognitive deficits and psychiatric disturbances. ${ }^{1}$ The neuropathological hallmark of Huntington's disease is neostriatal neuronal loss, but more wide pathology, especially of the frontal cortex, is also found. ${ }^{23}$

The major neuropsychological ' deficits in Huntington's disease are slow thinking, impaired ability to operate on acquired knowledge and to shift attention, and deficits in learning new verbal and non-verbal information. ${ }^{4}$ These psychological deficits have been traditionally attributed to pathology in cortical structures, while motor deficits have been associated with striatal pathology. However, work in primates has

Address for reprint requests: Sergio E Starkstein, MD. Meyer 4119, Department of Psychiatry, Johns Hopkins University School of Medicine, 600 N. Wolfe St., Baltimore, MD 21205, USA.

Received 2 February 1988 and in revised form 13 April 1988. Accepted 15 April 1988 demonstrated that the caudate nucleus receives input from cortical areas involved in cognitive functions, while the putamen mainly receives motor-related input. ${ }^{4}$

In this study, we assessed clinical features quantitatively and related them to quantitated $\mathrm{CT}$ scan measurements. The results are consistent with the view that the cognitive deficits are related to CT scan measurements of caudate nucleus and not cortical atrophy.

\section{Material and methods}

Subjects: Thirty-four Huntington's disease patients attending the Huntington's Disease Clinic at the Johns Hopkins Hospital were included in the study. Criteria for definitive Huntington's disease ${ }^{5}$ were (1) chorea or the characteristic impairment of voluntary movement, which was not present at birth, was insidious in onset, and which had become gradually worse, and (2) a family history of at least one other member with these typical symptoms of Huntington's disease. Every patient was examined prior to CT with a battery which consisted of (1) the Quantitated Neurological Examination, ${ }^{6}$ which includes a Chorea Scale, a Motor Impairment Scale and an Eye Movement Scale, (2) The Mini-Mental State Exam, ${ }^{7}$ and (3) the Huntington's 
Disease Activities of Daily Living Scale ${ }^{8}$ (which examines adaptive functioning in the areas of personal care, household activities, work and money).

Eighteen of the 34 patients were examined using a more detailed neuropsychological evaluation, which included the following tasks: Arithmetic, Vocabulary, Picture Arrangement and Block Design subtests from the Wechsler Adult Intelligence Scale, ${ }^{9}$ Temporal Orientation Test, ${ }^{10}$ Trail Making Test ${ }^{11}$ (Trails $B$ was given to 16 patients) and Symbol Digit Modalities Test (oral and written). ${ }^{12}$ These tests were selected on the basis of their established sensitivity to decline in Huntington's disease. ${ }^{8}$ None of the patients was on psychotropic medication at the time of neuropsychological evaluation.

CT Analysis: CT was performed on a Somaton DR3 or AS\&E scanners at $0^{\circ}$ from the orbitomeatal line, and ten $10 \mathrm{~mm}$-thick slices were obtained. One rater (SES), who was blind to the clinical and neuropsychological data, performed the following linear measurements of cortical and subcortical atrophy ${ }^{13}$ : Bifrontal ratio: (BFR: distance between the tips of the frontal horns divided by the distance between the inner tables of the skull along the same line, multiplied by 100 ), Bicaudate ratio (BCR: minimal distance between the caudate indentations of the frontal horns divided by the distance between the inner tables of the skull along the same line, multiplied by 100), Frontal fissure ratio (FFR: maximal width of the interhemispheric fissure at the frontal level divided by the trans-pineal coronal inner table diameter, multiplied by 100 ), and the Four cortical sulci ratio (4CSR: sum of widths of the four widest sulci divided by the transpineal coronal inner table diameters, multiplied by 100).

Statistical analysis was carried out by means of Pearson's correlations and multiple regression analysis. Owing to the number of correlations performed, the alpha level for their statistical significance was set at 0.01 .

\section{Results}

Demographic variables

Sample characteristics for the 34 Huntington's disease patients examined and the 18 Huntington's disease patients who undwerwent the detailed neuropsychological evaluation are given in table 1 .

Table 1 Demographic variables

\begin{tabular}{lll}
\hline & Group A & Group B \\
\hline Number of patients & 34 & 18 \\
Age (mean years) & $49 \cdot 29(15 \cdot 68)$ & $47 \cdot 06(13 \cdot 17)$ \\
Sex (\% females) & 62 & 33 \\
Race (\% whites) & 76 & 78 \\
Age of onset (years) & $42 \cdot 74(14 \cdot 41)$ & $41 \cdot 00(14 \cdot 05)$ \\
Duration of the disease & $6 \cdot 5(5 \cdot 9)$ & $6 \cdot 0(5 \cdot 1)$ \\
(mean years) & $11 \cdot 23(3 \cdot 54)$ & $11 \cdot 61(5 \cdot 54)$ \\
Education (mean years) & $23 \cdot 3(4 \cdot 8)$ & $24 \cdot 5(3 \cdot 6)$ \\
Mini-Mental State Exam & $16 \cdot 7(12 \cdot 5)$ & $18 \cdot 4(10 \cdot 9)$ \\
Activities of Daily Living & Group A: includes the total group of 34 Huntington's disease patients \\
examined. & \\
Group B: includes the group of 18 Huntington's disease patients who \\
underwent detailed neuropsychological evaluation.
\end{tabular}

Standard deviations are in parentheses.

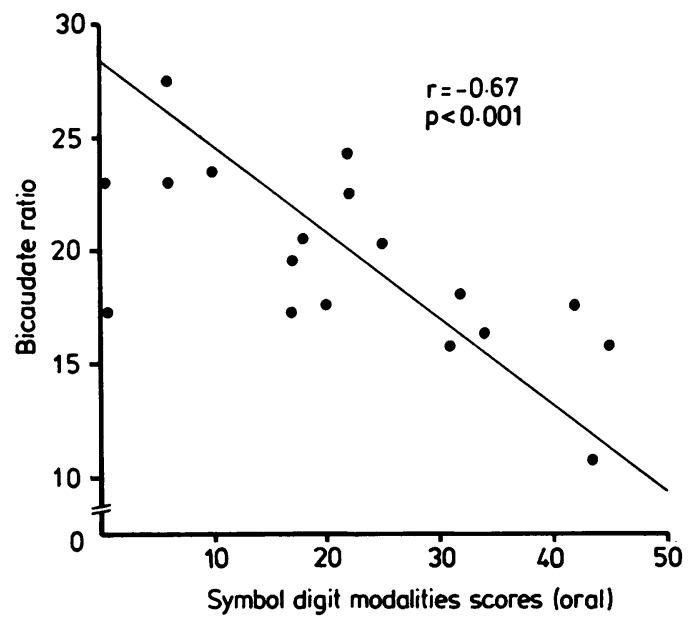

Fig 1 Relationship between the BCR and Trails B (time).

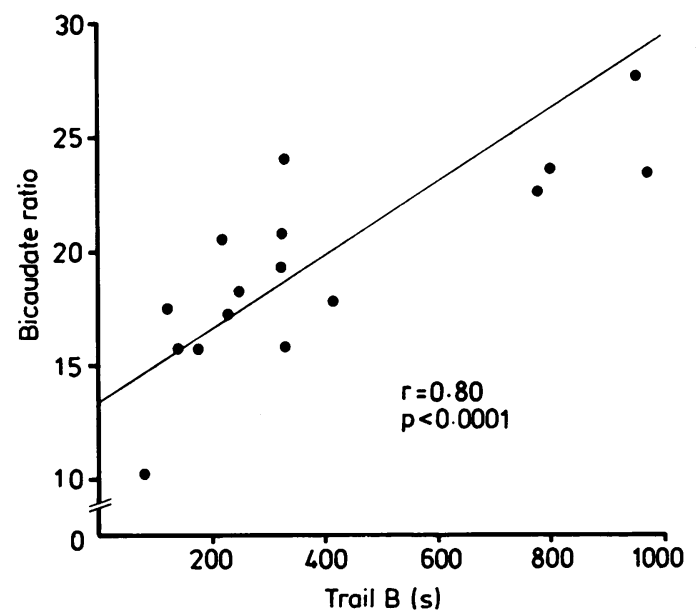

Fig 2 Relationship between the BCR and Symbol Digit Modalities Scores (oral).

Table 2 Correlations between CT scan measurements and clinical findings

\begin{tabular}{|c|c|c|c|c|}
\hline$(n=34)$ & $B C R$ & $B F R$ & $F F R$ & $4 C S R$ \\
\hline $\begin{array}{l}\text { Quantitated Neurologic } \mathrm{r}= \\
\text { Exam (Total score) } \mathrm{p}= \\
\text { Motor Impairment } \\
\quad \text { Score } \\
\text { Chorea Score } \\
\text { Eye Movement } \\
\text { Score } \\
\text { Activities of Daily } \\
\text { Living }\end{array}$ & $\begin{array}{l}0.48 \\
0.004 \\
0.23 \\
\text { NS } \\
0.13 \\
\text { NS } \\
0.44 \\
0.007 \\
0.57 \\
0.001\end{array}$ & $\begin{array}{l}0 \cdot 07 \\
\text { NS } \\
0 \cdot 18 \\
\text { NS } \\
0 \cdot 14 \\
\text { NS } \\
0 \cdot 16 \\
\text { NS } \\
0 \cdot 14 \\
\text { NS }\end{array}$ & $\begin{array}{l}0.05 \\
\text { NS } \\
0.47 \\
0.003 \\
0.00 \\
\text { NS } \\
-0.07 \\
\text { NS } \\
0.06 \\
\text { NS }\end{array}$ & $\begin{array}{l}0.07 \\
\text { NS } \\
0.25 \\
\text { NS } \\
-0.04 \\
\text { NS } \\
-0.09 \\
\text { NS } \\
0.28 \\
\text { NS }\end{array}$ \\
\hline
\end{tabular}

NS: not significant. 
Neurological variables and CT scan examination Severity of neurological impairment (total score on the Quantitated Neurologic Exam) significantly positively correlated with the degree of caudate atrophy (BCR) (table 2). The Motor Impairment Scale showed a significant correlation only with the FFR, while the Chorea Score showed no significant correlations with any of the CT scan measurements. The Eye Movement Scale score showed a significant correlation with the BCR, and there was also a significant correlation between Activities of Daily Living scores and the BCR (table 2). The Mini-Mental State Exam correlated significantly with the BCR only.

Neuropsychological variables and CT scan examination Means, standard deviations, and ranges for the neuropsychological tests assessed on the 18 Huntington's disease patients, as well as the normal range for each test (norms from an age and education comparable population) are shown in table 3.

Significant correlations were observed between the BCR and the following tests: Symbol Digit Modalities (oral (fig 1) and written), and both parts A and B of the Trail Making Test (table 4) (fig 2). None of the CT parameters correlated with any of the WAIS subtests or the Temporal Orientation Test.

Table 3 Means, SDs and ranges of neuropsychological scores for Huntington's disease patients

\begin{tabular}{|c|c|c|c|}
\hline \multirow{2}{*}{$\overline{W A I S}$} & $\begin{array}{l}\text { Huntington's } \\
\text { Mean (SD) }\end{array}$ & Huntington's disease patients & $\begin{array}{l}\text { Nonts } \\
\text { Normal Range }\end{array}$ \\
\hline & & & \\
\hline Arithmetic & $5.55(3.09)$ & $0-13$ & $\geq 8$ \\
\hline Vocabulary & $8.61(4.70)$ & $0-15$ & $\geq 8$ \\
\hline Picture Arrangement & $5 \cdot 22(2 \cdot 48)$ & $0-9$ & $\geq 8$ \\
\hline Block Design & $4.88(3.28)$ & $0-10$ & $\geq 8$ \\
\hline Temporal Ŏrientation & & & \\
\hline $\begin{array}{l}\text { Test (errors) } \\
\text { Trails A (s.) }\end{array}$ & $\begin{array}{c}5 \cdot 22(14 \cdot 1) \\
127 \cdot 7^{(66 \cdot 2)}\end{array}$ & $\begin{array}{c}0-61 \\
42-279\end{array}$ & $\begin{array}{l}\leq 3 \\
\leq 45^{*}\end{array}$ \\
\hline Trails B (s.) & $403 \cdot 1(296.9)$ & $80-967$ & $\leq 100^{*}$ \\
\hline Symbol Digit (oral) & $22.0(13.9)$ & $0-45$ & $\geq 44 \dagger$ \\
\hline Symbol Digit (written) & $20.5 \quad(11.4)$ & $1-40$ & $\geq 38 \dagger$ \\
\hline
\end{tabular}

-Represents 25 th percentile of $40-49$ year-olds

tRepresents one SD below the mean for 45-54 year olds with $\leq 12$ years of education.

Table 4 Correlations between CT scan measurements and neuropsychological variables

\begin{tabular}{|c|c|c|c|c|}
\hline & $B C R$ & $B F R$ & $F F R$ & 4CSR \\
\hline $\begin{array}{l}\text { Mini Mental Score } r= \\
\text { Symbol Digit } \\
\text { Modalities (written) } \\
\text { Symbol Digit } \\
\text { Modalities (oral) } \\
\text { Trails A (time) } \\
\text { Trails B (time) }\end{array}$ & $\begin{array}{c}-0.49 \\
0.002 \\
-0.65 \\
0.002 \\
-0.67 \\
0.001 \\
0.72 \\
0.001 \\
0.80 \\
0.0001\end{array}$ & $\begin{array}{c}0.03 \\
\text { NS } \\
-0.30 \\
\text { NS } \\
-0.41 \\
\text { NS } \\
0.32 \\
\text { NS } \\
0.48 \\
\text { NS }\end{array}$ & $\begin{array}{c}-0.02 \\
\text { NS } \\
-0.04 \\
\text { NS } \\
-0.12 \\
\text { NS } \\
-0.18 \\
\text { NS } \\
-0.29 \\
\text { NS }\end{array}$ & $\begin{array}{c}0.06 \\
\text { NS } \\
-0.48 \\
\text { NS } \\
-0.47 \\
\text { NS } \\
0.43 \\
\text { NS } \\
0.48 \\
\text { NS }\end{array}$ \\
\hline
\end{tabular}

NS: not significant
A hierarchical multiple regression analysis was performed to examine the relation between Trails B, and BCR taking Trails A into account (by entering it into the regression equation first). Trails $B$ accounted for a significant portion of the variance in BCR $\left(r^{2}\right.$ increment $=0.09, F=5.65, p(0.05)$ after controlling for Trails A, which was also significantly correlated with BCR $(r=0.72, p<0.05)$.

\section{Discussion}

The present study examined correlations between atrophy in cortical and subcortical structures as assessed by CT and variables of motor and neuropsychological impairment in Huntington's disease patients.

While no correlations were observed between measurements of caudate atrophy (BCR) and severity of chorea, the BCR showed a significant correlation with the severity of eye movement abormalities. The strongest relationship was between caudate atrophy and impairment in cognition.

While the basal ganglia have been previously considered to have motor functions, recent work has demonstrated important anatomical and functional sub-systems in basal ganglia structures. ${ }^{14}$ DeLong and co-workers ${ }^{14}$ described five segregated "loops" that connect frontocortical areas with different basal ganglia structures. The putamen has functional and anatomical connections to motor-related cortical structures, particularly the supplementary motor cortex. The caudate nucleus, on the other hand, has no fibre connections with the motor cortex, except for the frontal eye fields. Its major cortical connections are with frontal areas with established cognitive functions, especially the dorsolateral and orbital frontal cortices, and with limbic cortical areas related to emotional function. ${ }^{1415}$ The lack of relationship between the caudate and motor function (except for ocular movements) is consistent with our failure to find significant correlations between chorea scores and scores of voluntary motor functions with caudate atrophy.

The only significant correlation between caudate atrophy and motor deficits was with the eye movement scores. It is well known that Huntington's disease patients have difficulty in initiating saccades, and also demonstrate slow saccades and fixation instability. ${ }^{16}$ Our present findings suggest that caudate atrophy is an important pathological correlate of abnormal eye movements in Huntington's disease patients and agree with Young et al's finding of a significant correlation between basal ganglia (caudate and putamen) metabolism and abnormal eyes movements. ${ }^{17}$ The influence of caudate atrophy upon eye movement functions may be explained by the presence 
of strong connections between the caudate nucleus and other regions involved in oculomotor movement, such as the frontal eye fields and the substantia nigra pars reticulata. ${ }^{14}$ Caudate pathology may disrupt this oculomotor loop, thus producing the abnormal eye movements seen in Huntington's disease patients. ${ }^{18}$

There was a significant correlation between the Mini-Mental State score and caudate atrophy. A more detailed neuropsychological evaluation showed that caudate atrophy was associated mainly with deficits in cognitive tasks that tap functions usually associated with the frontal lobe, such as Symbol Digit Modalities (which involves visual search, number transcription and rapid response execution) and Trails B (which involves visual scanning, multiple tracking, set shifting, and the conceptual ordering of stimuli). While Symbol Digit Modalities may be influenced by graphomotor speed (which is impaired in Huntington's disease patients secondary to their motor deficits), the correlation between Symbol Digit Modalities and BCR remained significant when the task was performed orally. In the case of the Trail Making test, even when the variance accounted for by Trails A was partialled out statistically (thus controlling for visual scanning and graphomotor speed), the correlation between BCR and Trails B still remained significant. This suggests that caudate atrophy is stongly related to impairments in multiple tracking and set shifting, as well as visual search and graphomotor speed. Sax et $a l^{19}$ also found significant correlations between BCR and several neuropsychological tests, with the highest being between the BCR and the Symbol Digit Modalities Test. Fisher $e t$ $a l^{20}$ demonstrated that Huntington's disease patients are substantially impaired on procedures such as Porteus Mazes, Wisconsin Card Sorting Test and Stroop Test, which, like Trails B, involve visuo-spatial planning and rapid mental processing. In the light of our present findings as well as those of Sax et al, ${ }^{20}$ it is possible that all these "frontal-type" deficits can also be related to caudate atrophy.

The finding of "frontal-type" neurophyschological deficits is consistent with a common observation of relatives of Huntington's disease patients, who describe problems with organising, sequencing and planning, as well as an inability to coordinate and initiate complex actions. ${ }^{21}$ Caine et al $^{21}$ suggested that Huntington's disease patients have a lack of cortical "executive" functions similar to that found in patients with frontal lobe lesions. However, Fisher et al. $s^{20}$ demonstration that the abilities to maintain a cognitive set and organise cognitive strategies are impaired in the early phases of Huntington's disease suggest that his evolution may be secondary to progressive caudate atrophy.

It is somewhat surprising that we could not find significant correlations between frontal atrophy and the "frontal" neuropsychological tasks we employed. This might be explained by the fact that our frontal lobe CT scan measurements did not include the dorsolateral frontal cortex (we have measured frontal cortex only at the level of the interhemispheric fissure), or that other tasks, such as the Wisconsin Card Sorting Test, might be more sensitive. It is also possible that frontal metabolism, rather than atrophy, is related to neuropsychological deficits. Leenders $e t$ $a l^{22}$ have recently reported the case of an Huntington's disease patient who presented signs of intellectual deterioration (mainly on "frontal" tasks) who showed decreased oxygen and glucose metabolism and decreased cerebral blood flow in the frontal cortex in the absence of significant frontal atrophy. However, this patient also showed caudate atrophy, so that the relationship between frontocortical hypometabolism, caudate atrophy and frontal-type neuropsychological deficits will need further study.

In conclusion, the present study suggests that subcortical atrophy, especially in the caudate nucleus, parallels the cognitive decline in Huntington's disease, while cortical atrophy does not. Caudate pathology is not reflected in chorea or disorders of voluntary axial movements, but is reflected in abnormal oculomotor behaviour and cognitive deficits. The cognitive parameters most highly associated with caudate atrophy as revealed by CT, in Huntington's disease patients are visual conceptual tracking, set shifting and psychomotor speed.

This study was partially supported by NINCDS, grants: NS16375 and NS24841; a grant from the University of Buenos Airies (SES), and a National Alliance for the Research in Schizophrenia and Depression (NARSAD) Fellowship Extension Award (SES).

\section{References}

1 Bruyn GW, Went LN. Huntington's chorea. In: Vinken PJ, Bruyn GW, Klawans HL, eds Handbook of Clinical Neurology, Vol 5 (49): Extrapyramidal Disorders. Amsterdam, North Holland: Elsevier, 1986;267-313.

2 Bruyn GW, Bots GTAM, Dom R, Huntington's chorea: current neuropathological status. In: Chase TN, Wexler NS and Barbeau A (eds.). Advances in Neurology, Vol. 23. New York: Raven Press 1979;83-93.

3 Dom R, Malfroid M, Baro F. Neuropathology of Huntington's chorea. Neurology 1976;26:64-68.

4 Brandt J, Butters N. The neuropsychology of Huntington's disease. Trends In Neuroscience 1986;9:118-20.

5 Folstein SE, Leigh RJ, Parhad IM, Folstein MF. The diagnosis of Huntington's disease. Neurology 1986;36:1279-83.

6 David AS, Jeste DV, Folstein MF, Folstein SE. Volun- 
tary movement dysfunction in Huntington's disease and tardive dyskinesia. Acta Neurol Scand 1987;75:130-9.

7 Folstein MF, Folstein SE, McHugh PR. "Mini mental state". A practical method for grading the cognitive state of patients for the clinician. $J$ Psychiatr Res 1975;12:189-198.

8 Brandt J, Strauss ME, Larus J, Jensen B, Folstein SE, Folstein MF. Clinical correlates of dementia and disability in Huntington's disease. $J$ Clin Neuropsychol 1984;6:401-12.

9 Wechsler D. Wechsler Adult Intelligence Scale Manual. New York: Psychological Corporation, 1955.

10 Benton AL, De Hamsher K, Varney NR, Spreen O. Contributions to Neuropsychological Assessment. New York: Oxford University Press, 1983.

11 Reitan RM. Trail Making Test. Percept Mot Skills 1958;8:271-277.

12 Smith A. Symbol Digit Modalities Test Manual. Los Angeles: Western Psychological Services, 1973.

13 Gomori JM, Steiner I, Melamed E, Cooper G. The assessment of changes in brain volume using combined linear measurements: A CT-scan study. Neuroradiology 1984;26:21-24.

14 Alexander GE, DeLong MR, Strick PL. Parallel organisation of functionally segregated circuits linking basal ganglia and cortex. Ann Rev Neurosci 1986;9:357-81.

15 Selemon LD, Goldman-Rakic PS. Longitudinal topography and interdigitation of cortico-striatal projections in the rhesus monkey. $J$ Neurosci 1985;5:776-94.

16 Leigh RJ, Newman SA, Folstein SE, Lasker AG, Jensen BA. Abnormal ocular motor control in Huntington's chorea. Neurology 1983;33:1258-75.

17 Young AB, Penney JB, Starosta-Rubinstein S, et al. PET scan investigations of Huntington's disease: Cerebral metabolic correlates of neurological features and functional decline. Ann Neurol 1986;20:296-303.

18 Lasker AG, Zee DS, Hain TC, Folstein SE, Singer HS. Saccades in Huntington's disease: initiation defects and distractability. Neurology 1987;37:364-70.

19 Sax D, O’Donnell B, Butters N, Menzer L, Montgomery $\mathrm{K}$, Kayne HL. Computed tomographic, neurologic, and neuropsychological correlates of Huntington's disease. Int J Neurosci 1983;18:21-36.

20 Fisher JM, Kennedy JL, Caine ED, Shoulson I. Dementia in Huntington disease: a cross-sectional analysis of intellectual decline. In: Mayeux $\mathbf{R}$ and Rosen WG, eds. The Dementias. New York: Raven Press, 1983:229-38.

21 Caine ED, Fisher JM. Dementia in Huntington's disease. In: Frederiks JAM, ed. Handbook of Clinical Neurology, vol 46: Neurobehavioural Disorders. Amsterdam: Elsevier, 1985:305-10.

22 Leenders KL, Frackowiak RSJ, Quinn N, Marsden CD. Brain energy metabolism and dopaminergic function in Huntington's disease measured in vivo using positron emission tomography. Movement Disorders 1986;1:69-77. 